\title{
Sleep habits and height at ages 5 to 11
}

\author{
M C Gulliford, C E Price, R J Rona, S Chinn
}

\begin{abstract}
Shorter durations of slow wave sleep and lower growth hormone responses have been reported in children with short stature caused by psychosocial deprivation. We investigated whether lower total sleep duration was associated with shorter stature in a sample of children taking part in the National Study of Health and Growth. Parental responses to a self administered questionnaire were used to estimate usual times for going to sleep at night and usual times for waking in the morning for 5145 children aged 5 to 11 years of age. After adjusting for the effects of other variables known to be associated with height, it was shown that there was a weak negative association between sleep duration and height. It is concluded that variation in sleep duration between children is unlikely to have an important influence on growth.
\end{abstract}

Disordered sleep has been reported in children investigated because of short stature. ${ }^{1}$ One factor that relates sleep to growth is the diurnal variation in growth hormone secretion: there is a profound increase in circulating growth hormone concentrations during the night, ${ }^{2}$ and this increment is particularly associated with the onset of deep or slow wave sleep. ${ }^{3}$ In children with short stature caused by psychosocial deprivation, deficient slow wave sleep and reduced growth hormone secretion have been reported $^{14}$; this could contribute to the child's delayed growth. It is not known whether the total sleep duration has a quantitative influence on nocturnal growth hormone secretion or on children's growth. We therefore estimated sleep duration and its relation to height in children taking part in the National Study of Health and Growth. In this paper we report the results of this investigation together with the results of a descriptive analysis of the children's sleep habits and their relation to a number of social and biological variables.

Community Medicine,

United Medical and

Dental Schools of Guys and St Thomas's

Hospitals, London

M C Gulliford

C E Price

R J Rona

$\mathrm{S}$ Chinn

Correspondence to:

Dr M C Gulliford Department of

Community Medicine,

United Medical and

Dental Schools of Guys and

St Thomas's Hospitals,

St Thomas's Campus,

London SE1 7EH.

Accepted 28 August 1989 questionnaire to complete and the height, weight, and triceps skinfold thickness of the children are measured.

\section{Subjects and methods} National Study of Health and Growth in This is a survey of schoolchildren aged 5 years which has taken place annually since
SUBJECTS

A total of 9913 children took part in the 1987 survey. The sampling procedure has been described previously. ${ }^{6}$ The sample included children from England and Scotland. In England the sample was selected so as to include a high proportion of children from ethnic minority groups or from disadvantaged social backgrounds; in Scotland the sample was representative of the Scottish population.

\section{PROCEDURES}

In 1987 the questionnaire used in the study included two questions concerning the child's sleep. These were as follows: (1) at about what time does he or she usually go to sleep at night: (a) before a schoolday? (b) when there is no school the next day? (2) At about what time does he or she usually wake up in the morning: (a) on schooldays? (b) on days when there is no school? Answers were given in hours and minutes.

Parents were also asked to give information about the child's birth weight, the heights of the parents, the number of children in the family, the father's employment state and occupation, and the education of the mother. The number of people in the family divided by the number of rooms occupied (excluding bathroom and kitchen) was used as an index of overcrowding. The ethnic group of the children was classified according to the language spoken at the child's home as well as by the fieldworkers' subjective assessment of the child's ethnic group. This information was used to define the groups: 'Caucasian', Afro-Caribbean, Urdu, Gujarati, Punjabi, other Asian, and 'others'. ${ }^{6}$ The children's heights were measured at school by school nurses supervised by a full time field worker. Height was measured on a portable Holtain stadiometer to the nearest complete $0.1 \mathrm{~cm}^{7}$

\section{ANALYSIS}

Mean times for going to sleep and for waking up and mean sleep durations were calculated by age and sex. A height standard deviation (SD) score was calculated for each child by comparing the child's height with the mean and SD for the same age and sex obtained for a representative sample of children measured in 1986. This method of expression standardises for the increased variation in height between the ages of 5 and 11 and removes the effects of age on height. Multiple regression was used to assess the independent effect of sleep duration on 
height. ${ }^{8}$ Independent variables included seven continuous variables: the age and birth weight of the child, the parent's heights, the age of the mother on finishing full time education, the index of overcrowding, and the child's sleep duration. Because of the difference in sleep duration between schooldays and non-schooldays sleep duration was entered as the total duration of sleep during the week (schooldays times five plus weekends times two). Six categorical variables were included: the gender of the child, the number of children in the family, the ethnic group of the child, the country of residence (England or Scotland), the father's social class, and the father's employment state. Social class was divided into five categories: non-manual skilled manual, semiskilled and unskilled manual, not known or unclassifiable, and a category for children living with a single mother. Father's employment was classified into six groups: employed, unemployed for less than 12 months, unemployed for more than 12 months, unemployed when the length of time was unspecified, not known, and not known when a child was living with a single mother. An interaction term was included to allow for differences in the effects of family size in the different ethnic groups.

Multiple regression was also employed to evaluate the effects of a number of variables on sleep duration. Independent variables included all those defined above except for the child's birth weight and the parent's heights, which were excluded. An interaction term for ethnic group and family size was again included. Mean

Table 1 Mean (SD) sleep duration by age and sex (hours, minutes)

\begin{tabular}{lllll}
\hline $\begin{array}{l}\text { Age } \\
\text { (years) }\end{array}$ & Sex & $\begin{array}{l}\text { No } \\
\text { of children }\end{array}$ & \multicolumn{2}{c}{ Sleep duration } \\
Schoolday & Weekend \\
\hline 5 & M & 439 & $11,16(0,45)$ & $11,06(0,58)$ \\
& F & 380 & $11,17(0,44)$ & $11,14(0,55)$ \\
6 & $M$ & 471 & $11,09(0,42)$ & $10,55(0,56)$ \\
7 & F & 401 & $11,08(0,44)$ & $11,00(0,52)$ \\
& M & 453 & $10,55(0,41)$ & $10,44(0,53)$ \\
8 & M & 363 & $11,01(0,46)$ & $10,55(0,58)$ \\
& F & 391 & $10,44(0,39)$ & $10,40(0,54)$ \\
9 & $M$ & 376 & $10,50(0,44)$ & $10,53(0,59)$ \\
& F & 351 & $10,35(0,38)$ & $10,30(0,57)$ \\
10 & M & 351 & $10,41(0,37)$ & $10,47(0,55)$ \\
& F & 341 & $10,26(0,40)$ & $10,29(0,62)$ \\
11 & M & 211 & $10,23(0,38)$ & $10,45(0,55)$ \\
& F & 205 & $10,11(0,38)$ & $10,26(0,64)$ \\
& & & $10,20(0,38)$ & $10,44(0,58)$
\end{tabular}

values for sleep duration at different levels of categorical variables were estimated by adjusting for the unbalanced distribution of other variables included in the analysis. ${ }^{9}$ Children from Asian backgrounds were grouped as a single class in order to allow estimation of class means.

\section{Results}

Height SD scores were obtained on 9140 children aged 5 to 11 years. After exclusion of missing values, complete data for the variables included in the analysis were obtained on 5145 children. The exclusion of cases containing missing values changed the mean height SD score by 0.04 units and the mean sleep duration by two minutes.

Unadjusted mean times for going to sleep, for waking up, and for sleep duration are given by age and sex in tables 1 and 2. It can be seen that sleep habits differ on schooldays and on nonschooldays. Multiple regression showed that five factors were significantly associated with sleep duration: these were the child's age, gender, ethnic group, family size, and social class. Sleep duration was not associated with overcrowding in the home, with paternal unemployment, or with educational attainment of the mother. Adjusted mean sleep durations for schooldays and weekends are given by gender, social class, and ethnic group in table 3. Sleep duration was slightly longer in girls than in boys both on schooldays $(p<0.01)$ and non-

Table 3 Adjusted mean (SE) sleep duration on schooldays and at the weekend, by gender, social class, and ethnic group (hours, minutes)

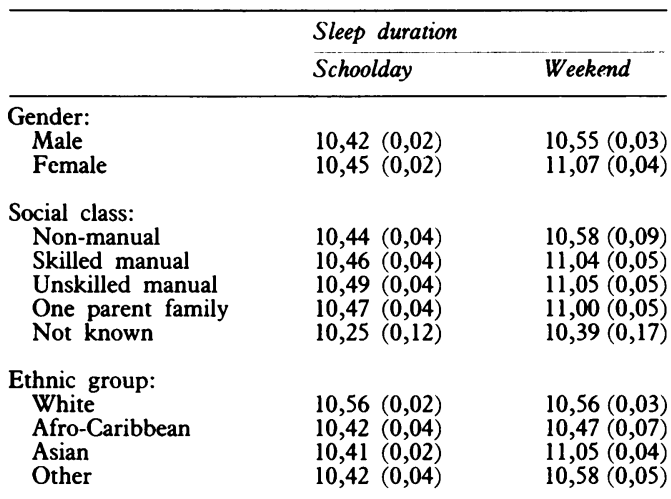

Table 2 Mean (SD) times for going to sleep and for waking up by age and sex (hours, minutes)

\begin{tabular}{lllllll}
\hline $\begin{array}{l}\text { Age } \\
\text { (years) }\end{array}$ & Sex & $\begin{array}{l}\text { No } \\
\text { of children }\end{array}$ & $\begin{array}{l}\text { Sleeps } \\
\text { Schoolday }\end{array}$ & Weekend & Schoolday & Weekend \\
\hline 5 & M & 439 & $20,14(0,46)$ & $21,01(0,52)$ & $7,30(0,32)$ & $8,07(0,62)$ \\
& $\mathrm{F}$ & 380 & $20,16(0,44)$ & $20,57(0,52)$ & $7,33(0,28)$ & $8,11(0,54)$ \\
6 & $\mathrm{M}$ & 471 & $20,24(0,42)$ & $21,11(0,47)$ & $7,33(0,29)$ & $8,07(0,57)$ \\
& $\mathrm{F}$ & 401 & $20,24(0,46)$ & $21,10(0,51)$ & $7,32(0,31)$ & $8,10(0,56)$ \\
7 & $\mathrm{M}$ & 453 & $20,38(0,41)$ & $21,25(0,44)$ & $7,32(0,31)$ & $8,08(0,58)$ \\
& $\mathrm{F}$ & 363 & $20,34(0,40)$ & $21,23(0,45)$ & $7,35(0,26)$ & $8,19(0,58)$ \\
8 & $\mathrm{M}$ & 412 & $20,49(0,38)$ & $21,32(0,41)$ & $7,33(0,26)$ & $8,13(0,58)$ \\
& $\mathrm{F}$ & 391 & $20,44(0,42)$ & $21,30(0,47)$ & $7,35(0,28)$ & $8,23(0,58)$ \\
9 & $\mathrm{M}$ & 376 & $21,01(0,37)$ & $21,47(0,45)$ & $7,37(0,26)$ & $8,17(0,61)$ \\
& $\mathrm{F}$ & 351 & $20,55(0,35)$ & $21,41(0,40)$ & $7,35(0,25)$ & $8,28(0,54)$ \\
10 & $\mathrm{M}$ & 351 & $211(0,38)$ & $21,41(0,40)$ & $7,35(0,25)$ & $8,27(0,60)$ \\
& $\mathrm{F}$ & 211 & $211(0,35)$ & $21,55(0,40)$ & $7,34(0,27)$ & $8,40(0,58)$ \\
11 & $\mathrm{~F}$ & 205 & $21,14(0,34)$ & $22,10(0,45)$ & $7,36(0,29)$ & $8,35(0,65)$ \\
& & & $22,05(0,40)$ & $7,34(0,25)$ & $8,48(0,56)$ \\
\hline
\end{tabular}


Table 4 Variables associated with height SD scores of children in England and Scotland in multiple regression model

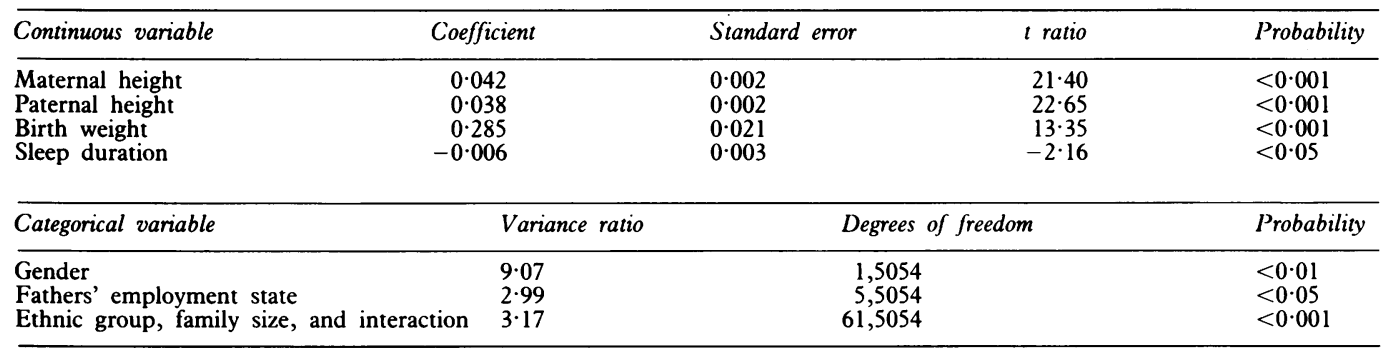

schooldays ( $p<0.001)$. The effect was accounted for by earlier times of going to sleep and later times for waking in girls. The social class of the father was not associated with sleep duration on schooldays but at the weekend sleep durations were shorter in children of fathers with nonmanual occupations than in children of fathers with manual occupations $(p<0.01)$.

Children of white origin slept for longer on schooldays than children of Afro-Caribbean or Asian origin (table 3). On non-schooldays Asian children showed longer sleep duration but over a seven day week the sleep duration in AfroCaribbean and Asian children was less than in white children. When the children were considered as a single group, the number of children in the family was not associated with sleep duration on schooldays. However, a significant interaction with the ethnic group of the child was noted. In children of white origin sleep duration increased with increasing family size, whereas in the other ethnic groups there was no consistent effect of family size. On nonschooldays sleep duration increased with family size without a significant difference in trend between the ethnic groups.

Seven variables were significantly associated with the height SD scores of the children, the gender of the child, the father's employment state, the ethnic group of the child, and the number of children in the family as well as the birth weight of the child and his parents' heights. When the total duration of sleep over a seven day week was entered into the model there was a weak negative association between the child's height and the observed sleep duration (table 4).

\section{Discussion}

In this study we used parental responses to a self administered questionnaire to estimate the child's sleep duration. Although electroencephalographic measurement of sleep duration is considered to be more accurate than subjective assessment, ${ }^{10}$ the use of a sleep questionnaire in normal adults gives results that are correlated with results obtained by the electroencephalographic method. ${ }^{11}$ In addition, the use of a questionnaire lends itself to use in large scale surveys, which can evaluate the effects of social and other factors on sleep duration and quality throughout the week. ${ }^{12}$ In children the use of parental responses may overestimate sleep duration as parents may tend to report times for going to bed and for rising rather than times for going to sleep and waking. We did not specifically evaluate this effect but present our results in relation to the wording of the question that was asked of the parents.

Despite the social importance of sleep in children, reports containing quantitative information concerning sleep duration in children at different ages are infrequent. Roffwarg et al characterised sleep electroencephalographically for a small number of children of different ages, ${ }^{13}$ and these data were subsequently extended by Coble $e t a^{14}$; neither group was able to relate their findings to the social and biological context of the child. In a longitudinal study of 200 Swedish children Klackenberg, using subjective methods, documented the decline in sleep duration from 14 hours per night at 1 year to 10 hours per night at 16 years. ${ }^{15}$ The values given over the range of ages are similar to those obtained in a larger sample of British children in the present investigation. Both studies give longer durations for sleep than those reported from electroencephalographic measurement.

In addition to the dominant effect of the child's age in determining the time for going to sleep and for waking, our analysis identified several other factors associated with sleep habits. Effects of gender and social class on sleep habits of older children have been noted previously. ${ }^{16}$ In the present study these factors had significant effects that were of small amplitude. Differences in sleep habits between ethnic groups were also demonstrated.

Children from Afro-Caribbean and Asian families slept for significantly shorter durations on schooldays; despite an increase in sleep at the weekend, the total duration of sleep during the week was reduced. This difference was still evident after adjusting for a number of other variables including family size. Previous investigations have suggested that family size is positively associated with later bedtimes and reduced time spent in bed in adolescents. ${ }^{17}$ In our sample larger family size was not associated with shorter sleep duration, however, but rather with increased sleep duration in white families only. The different ages of the children investigated in the two samples as well as their different social and ethnic characteristics 617 might have accounted for this discrepancy. The difference in sleep habits between ethnic groups is thus not accounted for by factors included in the analysis.

Previous analyses of children's height from the National Study of Health and Growth have identified a number of factors that are associated with height in primary schoolchildren. 
These include the child's birth weight, the heights of the parents, the ethnic background of the child, and a number of social factors including the father's social class, his employment state, and the number of children in the family. ${ }^{6} 18$ The association between the gender of the child and height in this analysis resulted from the calculation of height SD scores using data from the representative sample, which results in a different bias in boys than girls. ${ }^{6}$ Recent work has shown that disorders of sleep may be present in children investigated for short stature. ${ }^{1}$ This would be consistent with the known association of growth hormone release with slow wave sleep. ${ }^{3}$ We were therefore interested to examine, in a population sample, the possibility that sleep duration could be associated with height in children of primary school age. After adjusting for confounding variables this analysis showed a weak negative correlation between the child's height and the total duration of sleep over a seven day period. There was therefore no evidence to support an association between longer sleep duration and increased growth. The finding of a weak association between increased height and reduced sleep duration is contrary to our initial hypothesis and is not readily explained. Further investigations would be needed to show whether this is a spurious association or whether identifiable factors influence this pattern of sleep. The findings of this observational study suggest, however, that reduced total sleep duration is not associated with reduced height in a population sample.

We thank the parents and children who have taken part in the study and acknowledge the work done by our colleagues in the study areas and in the department of community medicine at
St Thomas's Hospital. We thank Professor W W Holland for his continued support and encouragement. The study is funded by the Department of Health and the Scottish Home and Health Department.

1 Taylor BJ, Brook CGD. Sleep EEG in growth disorders. Arch Dis Child 1986;61:754-60

2 Hunter WM, Rigal WM. The diurnal pattern of plasma growth hormone concentration in children and adolescents. $\mathcal{F}$ Endocrinol 1966;34:147-53.

3 Takahashi Y, Kipnis DM, Daughaday WH. Growth hormone secretion during sleep. F Clin Invest 1968;47: 2079-90.

4 Guilhaume A, Benoit O, Gourmelen M, Richardet JM. Relationship between sleep stage IV deficit and reversible HGH deficiency in psychosocial dwarfism. Pediatr Res 1982;16:299-303.

5 Irwig LM. Surveillance in developed countries with particular reference to child growth. Int $\mathcal{F}$ Epidemiol 1976;5:57-61.

6 Rona RJ, Chinn S. National Study of Health and Growth Rocial and biological factors associated with height of
socilth social and biological factors associated with height of
children from ethnic groups living in England. Ann Hum children from ethnic

7 Tanner JM, Whitehouse RH, Takaishi M. Standards from birth to maturity for height, weight, height velocity and weight velocity. Arch Dis Child 1966;41:454-71.

8 Price CE, Rona RJ, Chinn S. Height of primary schoo children and parents' perceptions of food intolerance. $B$ Med F 1988;296:1696-9.

9 SAS Institute. SAS user's guide: statistics. (Version 5 edition.) Cary, North Carolina: SAS Institute, 1985:444-5.

10 Weiss BL, McPartland RJ, Kupfer DJ. Once more: the inaccuracy of non-EEG estimates of sleep. Am F Psychiatry 1973;130:1282-5.

11 Lewis SA. Subjective estimates of sleep: an EEG evaluation. Br f Psychol 1969;60:203-8.

12 Johns MW. Methods for assessing human sleep. Arch Intern Med 1971;127:484-92.

13 Roffwarg HP, Dement WC, Fisher C. Preliminary observations of the sleep-dream pattern in neonates, infants, children and adults. In: Harms E, ed. Problems of sleep and children and adults. In: Harms E, ed. Problems of sleep and

14 Coble PA, Kupfer DJ, Taska LS, Kane J. EEG sleep of normal healthy children. Part 1: Findings using standard measurement methods. Sleep 1984;7:289-303.

15 Klackenberg G. Sleep behaviour studied longitudinally: dat from 4-16 years on duration, night-awakening and bed sharing. Acta Paediatr Scand 1982;71:501-6.

16 Rugg-Gunn AJ, Hackett AF, Appleton DR, Eastoe JE. Bedtimes of 11-14 year old children in North-Eas England. F Biosoc Sci 1984;16:291-7.

17 MacGregor IDM, Balding JW. Bedtimes and family size in English schoolchildren. Ann Hum Biol 1988;15:435-41.

18 Rona RJ, Swan AV, Altman DG. Social factors and height of primary schoolchildren in England and Scotland. $\mathcal{J}$ Epidemiol Community Health 1978;32:147-54. 